\title{
Vocal-Acoustic Pathways in a Teleost Fish
}

\author{
Andrew H. Bass, ${ }^{1,2}$ Margaret A. Marchaterre, ${ }^{1,2}$ and Robert Baker ${ }^{3}$ \\ ${ }^{1}$ Section of Neurobiology and Behavior; Cornell University, Ithaca, New York 14853, ${ }^{2}$ Bodega Marine Laboratory, \\ University of California, Bodega Bay, California 94923, and ${ }^{3}$ Department of Physiology and Biophysics, New York \\ University Medical Center, New York, New York 10016
}

\begin{abstract}
Many teleost fish generate acoustic signals for vocal communication by the synchronized, high-frequency contraction of skeletal, sonic muscles. In midshipman, eight groups of brainstem neurons were distinguished after biocytin application to the sonic nerve that, we propose, represent the entire vocal motor circuit. Biocytin-filled terminals were ubiquitous within all areas containing labeled neurons and, together with ultrastructural evidence, suggested a serial, transneuronal transport at synaptic sites between at least three neuronal groups. The most intensely labeled neurons were positioned in the caudal brainstem and included a previously characterized pacemaker-motoneuron circuit and a newly recognized ventral medullary nucleus that itself gave rise to extensive commissural and lateral brainstem bundles linking the pacemaker circuitry to the rostral brainstem. Five additional groups formed a column rostrally within the medial brainstem adjacent to eighth nerve (octaval)-recipient nuclei largely presumed to be acoustic. This column extended dorsally up to the ventricular cell layer and as far anterior as midbrain isthmal levels. The best-defined group was in the octaval efferent nucleus that directly innervates the sacculus that is considered the auditory division of the inner ear. Saccular afferents and neurons throughout the medial column were also filled after biocytin application to the saccular nerve. This vocal-acoustic network overlaps low-threshold, electrical stimulation sites in the rostral brainstem that elicit vocalizations. The medial column must therefore be the origin of the descending pathway controlling activation of the vocal pacemaker circuitry and likely forms the basis for acoustically elicited vocalizations. We suggest this network, together with input from the pacemaker circuitry, is also the origin of a vocal-related, corollary discharge to acoustic nuclei. Direct links between vocal and acoustic brain regions are thus traits common to aquatic and terrestrial vertebrates.

[Key words: brainstem, pacemaker circuit, vocalization, acoustic, corollary discharge]
\end{abstract}

Teleost fishes generate acoustic communication signals important to both their survivorship and reproductive success (reviews: Bass, 1990, 1992). Among Batrachoidiformes, an order

Received Aug. 18, 1993; revised Dec. 16, 1993; accepted Dec. 21, 1993.

This work was supported from the National Science Foundation (BNS8708559, 9021563) and the National Institutes of Health (NS13742). Thanks to the Bodega Marine Laboratory for logistical support, Dr. M. Weiser for assistance with the figures, and Drs. H. Baker, M. Braford Jr., and C. McCormick for reading and commenting on the manuscript.

Correspondence should be addressed to Dr. Andrew H. Bass, Section of Neurobiology and Behavior, Mudd Hall, Cornell University, Ithaca, NY 14853.

Copyright (C) 1994 Society for Neuroscience $0270-6474 / 94 / 144025-15 \$ 05.00 / 0$ of marine fishes, sound is generated by the contraction of paired skeletal, sonic muscles attached to the lateral walls of the swim bladder (SM, Fig. 1A,B). From a comparative, evolutionary perspective with tetrapods, it is appropriate to classify the acoustic signals of these fish as vocalizations. Tetrapods use laryngeal, syringeal, and tongue musculature to vocalize. These sonic muscles share a number of traits with those of batrachoidid fishes including the production of species- and sex-typical acoustic signals, differentiation as skeletal muscles originating from occipital somites, and innervation by homologous sets of motoncurons: syringeal and tongue muscles are innervated by the hypoglossal motor nucleus, which is considered a homolog of the batrachoidid sonic motor nucleus (review: Bass, 1989).

In the plainfin midshipman (Porichthys notatus), a representative batrachoidid, the sonic motor nucleus (SMN, Fig. 1C) has a midline position at the caudal end of the brainstem and innervates the ipsilateral muscle via occipital nerve roots (OC, Fig. $1 C$ ). So far, extensive intracellular recording and staining studies in midshipman have identified individual pacemaker neurons, which lie adjacent to the sonic motor nucleus (PN, Fig. $1 C$ ), as the only source of direct synaptic input onto sonic motoneurons (Bass and Baker, 1990). Pacemaker neurons set the discharge frequency of the motoneurons, which then determines the contraction rate of the muscles and, in turn, the fundamental frequency of vocalizations. Individual pacemaker neurons innervate both motor nuclei, consistent with the hypothesis that their role is to synchronize motoneuron firing that leads to the simultaneous contraction of both muscles at the fundamental frequency. Thus, there is a direct relationship between the rhythmic, patterned output of a brainstem pacemaker circuit and the physical attributes of species- and sex-typical vocalizations.

One long-term goal of vocal motor studies in both anamniotes and amniotes has been to identify the neurons controlling the rhythmic discharge of the vocal pacemaker circuitry. While a number of studies in batrachoidid fishes had used electrical stimulation to elicit vocalizations at sites distant from the motor nucleus, the positions of neuronal groups forming a descending pathway were unknown (review: Bass and Baker, 1991). As mentioned above, intracellular studies have so far identified individual pacemaker neurons as providing the sole input to sonic motoneurons. Given the limitations of single-cell studies in delineating the complete extent and location of neurons within a circuit, a potential transneuronal tracer was sought to both map the entire complement of pacemaker neurons and identify their afferents. Biocytin, a complex of biotin and lysine, was chosen as a candidate transneuronal tracer for a number of reasons, foremost among which were its low molecular weight (372), diffusion throughout the soma-dendritic-axonal compartments of neurons, and high affinity for avidin, which made 


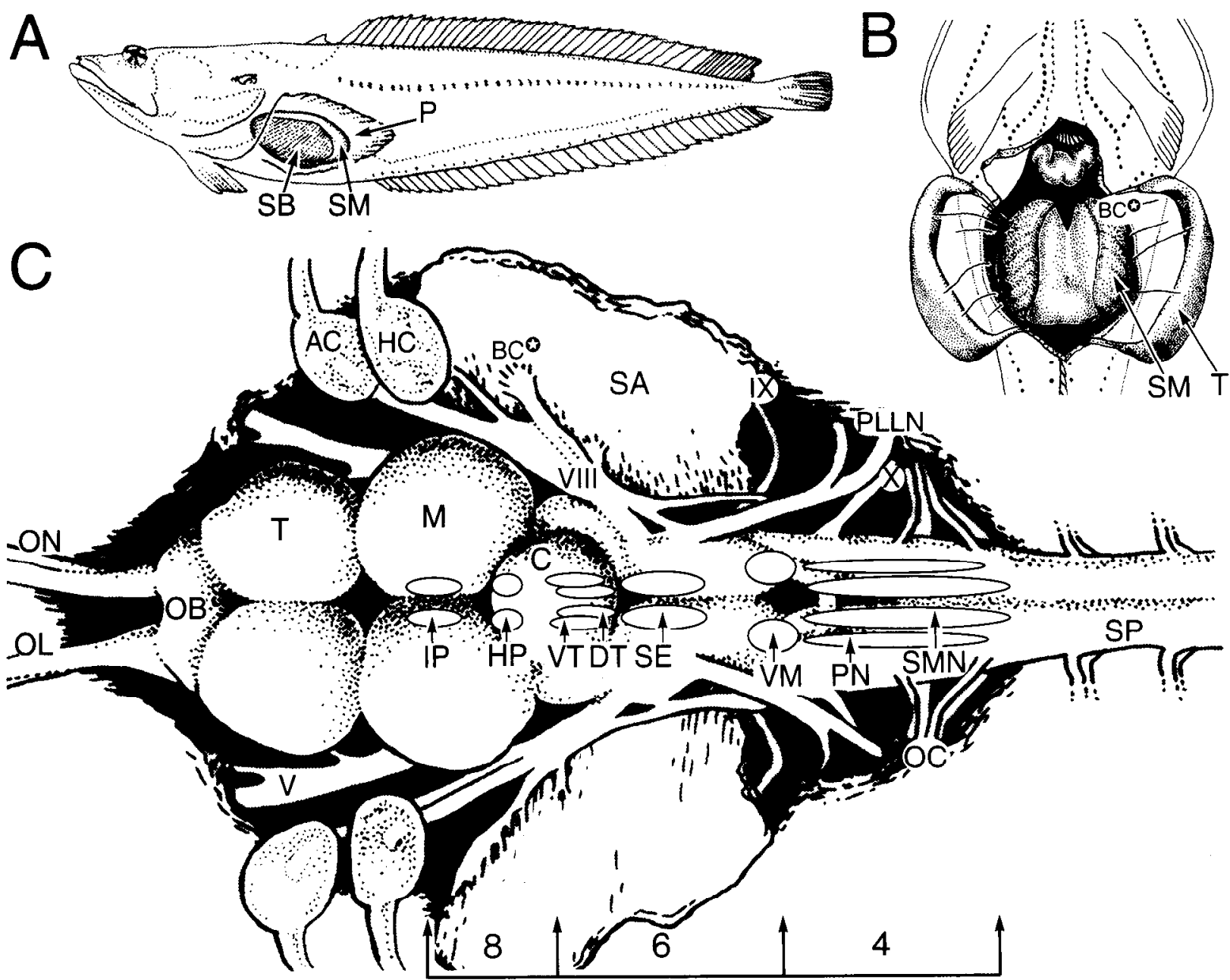

Figure 1. Overview of vocal motor system of midshipman. $A$, Line drawing of a lateral view of a plainfin midshipman (Porichthys notatus) showing the position of the swim bladder $(S B)$ and attached sonic muscles $(S M)$ at the level of the pelvic fin $(P)$. $B$, Line drawing of a ventral view of a male; the testes $(T)$ have been deflected to show the paired sonic muscles $(S M)$ attached to the swim bladder's walls. $C$, A schematic reconstruction superimposed on a dorsal view of the midshipman's brain showing the positions of the eight groups of biocytin-filled neurons labeled following biocytin labeling of the sonic nerve at the level of the swim bladder $\left(B C^{*}, B\right)$. The approximate anterior-posterior extent of the line drawings presented in Figures 4, 6, and 8 is indicated. $A C$, anterior canal ampulla; $C$, cerebellum; $D T$, dorsal tegmental group; $H C$, horizontal canal ampulla; $H P$, hindbrain paraventricular group; $I P$, isthmal paraventricular group; $M$, midbrain; $O B$, olfactory bulb; $O L$, olfactory nerve; $O C$, occipital nerves; $O N$, optic nerve; $P L L N$, posterior lateral line nerve; $P N$, pacemaker neurons; $S A$, saccular otolith; $S E$, statoacoustic efferent nucleus; $S M N$, sonic motor nucleus; $S P$, spinal cord; $T$, telencephalon; $V$, trigeminal nerve; $V M$, ventral medullary nucleus; $V T$, ventral tegmental group; $V I I I$, eighth nerve; $I X$, glossopharyngeal nerve; $X$, vagus nerve. Scale bar, $1 \mathrm{~mm}$.

it optimally suited for use with a variety of immunocytochemical markers (Horikawa and Armstrong, 1988). Surprisingly, biocytin labeling of the midshipman's sonic nerve at the level of the swim bladder delineated the full extent of the pacemaker circuitry and, more impressively, demonstrated a linkage between that circuitry and acoustic regions of the rostral brainstem extending up to midbrain levels. A vocal-acoustic linkage was further implied when, after biocytin labeling of the eighth nerve, which innervates the inner ear, transneuronal transport resulted in the filling of neurons that were also labeled via the sonic nerve.

Comparisons with neurophysiological studies indicate this vocal-acoustic network must include the pathway for descending control of the vocal pacemaker circuit, which, in part, could be activated by primary or higher-order acoustic inputs. We suggest that this vocal-acoustic circuit also includes a corollary discharge pathway by which vocal motor information reaches the acoustic system, analogous to convergences within the teleostean electrosensory/motor and the mammalian auditory/vo- cal systems (Suga and Shimozawa, 1974; Bell, 1989; Metzner, 1993). Finally, as reasoned here, if the entire complement of neurons in a vertebrate circuit can be delineated by a single application of a tracer to its most peripheral element, a motor or sensory nerve, then this technique has obvious advantages over most other tract-tracing methodologies, especially for small, nonmammalian vertebrates. The comprehensive mapping suggested here by biocytin provides an immediate guide to the causal analysis of a neuronal network, like a vocal motor circuit, determining the execution of a specific behavior, such as vocalizations.

Portions of these results were reported earlier (Bass et al., 1992).

\section{Materials and Methods}

This study included both adult and juvenile midshipman fish. Previous behavioral, morphological, and neurophysiological studies have characterized the vocal behavior and motor system of midshipman (Bass, 1992). Although vocalizations and motor traits differ both within and 
between sexes (Bass, 1992), the results presented here are characteristic of all groups; sex- and age-related polymorphisms will be presented elsewhere. The purpose here is to delineate the vocal-acoustic circuit using biocytin as a transneuronal tracer for identifying multisynaptic pathways.

Adults and juveniles were captured at field sites during the periods June-August, 1990-93. All animals were maintained in running seawater holding tanks at a temperature of $12-13^{\circ} \mathrm{C}$. and fed a regular diet of brine shrimp or surfperch. Following anesthetization with tricainc methanesulfonate (MS222, Sigma Chemical Co., St. Louis, MO), a ventral incision was made through the body wall to expose the ipsilateral sonic muscle. Biocytin (Sigma) was used in one of two ways: (1) as a $2 \%$ solution dissolved in teleost Ringer's (Cavanaugh, 1956) and injected into a single sonic muscle with a Hamilton syringe in volumes of 1-10 $\mu l$ depending on muscle size or (2) as crystals directly applied to the cut end of a single sonic nerve following exposure of the nerve which traverses the underside of the muscle (BC*, Fig. $1 B$ ). After application of biocytin, the ventrum was sutured shut, sealed with Vetbond (3M, St. Paul, MN), and the animal was returned to its home tank for recovery. The results presented here are hased on experiments in 38 sexually mature adults (standard length, $6.3-16.0 \mathrm{~cm}$ ), and 10 sexually immature juveniles $(4-11.5 \mathrm{~cm})$.

Following survival times ranging from 1 to $21 \mathrm{~d}$ for specimens with muscle injections ( $n=27$; mean survival time, $6.6 \mathrm{~d}$ ), or $0.5-13 \mathrm{~d}$ for specimens with crystal application $(n=21$; mean survival time, $7.4 \mathrm{~d})$, specimens were reanesthetized with MS222, perfused transcardially with cold teleost Ringer's followed by cold $4 \%$ paraformaldehyde, $1 \%$ glutaraldehyde dissolved in $0.1 \mathrm{M}$ phosphate buffer $(\mathrm{PB})$, and then postfixed for $1 \mathrm{hr}$ in the fixative. Brains were stored for $1-14 \mathrm{~d}$ in $\mathrm{PB}$ and cut frozen (after storage in 30\% sucrose-PB overnight) at $50 \mu \mathrm{m}$, or vibratomed at $70 \mu \mathrm{m}$, in the transverse, horizontal, or sagittal planes. Sections were stored in phosphate-buffered saline (PBS) and then processed with a procedure modified from that of Horikawa and Armstrong (1988): (1) washed twice, $10 \mathrm{~min}$ each, in PRS; (2.) incubated $30 \mathrm{~min}$ in $0.4 \%$ Triton-X in PBS; (3) incubated $3 \mathrm{hr}$ in an avidin:biotinylated horseradish peroxidase complex (Elite Kit, Vector Laboratories, Burlingame, CA); (4) washed $10 \mathrm{~min}$ in PBS; (5) washed twice in $0.05 \mathrm{M}$ Tris-HCl buffer for $10 \mathrm{~min}$ each; (6) incubated $1-2 \mathrm{~min}$ in $0.05 \%$ diaminobenzidine, $0.01 \%$ hydrogen peroxide dissolved in Tris buffer solution; (7) washed twice in PB; and (8) stored in PB until mounted on chrom-alum subbed slides. Selected slides were counterstained with cresyl violet; all slides were dehydrated in a graded series of alcohols and then coverslipped. In four other specimens (three juveniles, one adult), a single sonic nerve was labeled with dextran-biotin ( $10 \mathrm{kDa}$; Molecular Probes, Inc., Eugene, OR); survival times ranged from 1 to $6 \mathrm{~d}$. Tissue was processed as described above for biocytin.

There were also a number of experiments to control for specificity of uptake by the sonic nerve which inchuded biocytin labeling together with cutting of the ipsilateral or contralateral nerve rostral to its entrance to the sonic muscle at the level of the swim bladder (five adults, two juveniles; 2-12 d survival), and labeling of dorsal and ventral trunk, or pectoral and pelvic fin, muscles (four adults; 5-7 d).

In six adults, the saccular or anterior branch (which carries saccular fibers) of the eighth nerve was exposed on one side and labeled with biocytin crystals $\left(\mathrm{BC}^{*}\right.$, Fig. 1C) for 4-11 d to aid the identification of recently described brainstem octaval nuclei in this order of teleosts (Highstein and Baker, 1986; Highstein et al., 1992). The sacculus, which is the largest division of the inner ear in midshipman (SA, Fig. $1 C$ ), was the focus because it is considered the principal acoustic end organ in this and other species of teleosts (review: Popper and Fay, 1993).

Vibratome sections were obtained from the brains of two adults with biocytin labeling of the sonic nerve. The previous labeling protocol was carried out with omission of the Triton- $X$ incubation. Sections were then (1) postfixed for $1 \mathrm{hr}$ in $1.0 \%$ osmium tetroxide in $\mathrm{PB},(2)$ washed in distilled water, (3) dehydrated through an alcohol series, (4) washed in propylene oxide, (5) infiltrated with Polybed 812 , and (6) flat embedded. Thin sections were cut on an ultramicrotome and stained with Reynolds lead citrate and uranyl acetate. Photomicrographs were taken on a Philips 201 electron microscope.

\section{Results}

Biocytin methods

Biocytin-filled cells contained a homogeneous, dense, brown reaction product throughout the soma-dendritic and axonal compartments, giving them a Golgi-like appearance similar to retrogradely filled motoneurons (e.g., Fig. $2 A, C, G, H$ ). Crystal application to a severed sonic ncrve gave the most extensive pattern of transneuronal labeling in terms of cell number and rostral staining in the brainstem. The extent of transneuronal transport was also directly correlated to survival time for similarly sized specimens. At an ultrastructural level, biocytin label was similar to that described for Neurobiotin-labeled cells at injection sites (Huang et al., 1992). A diffuse reaction product was found within labeled terminals, axons, and dendrites ( $\mathrm{t}$, a, d, respectively, Fig. $3 A, B$ ); synaptic vesicles were uniformly coated with the reaction product (Fig. $3 B$ ). Adjacent unlabeled terminals (u, Fig. $3 B$ ) suggested selectivity of synaptic uptake sites.

A number of experiments controlled for specificity of biocytin transport. Labeling of one sonic nerve together with a proximal cut at the level of the swim bladder resulted in no central transport. Bilateral transneuronal transport usually occurred throughout the vocal motor circuit after cutting the contralateral nerve. Thus, retrograde transport from either a single sonic muscle or nerve accounted for the entire bilateral pattern of transneuronal transport described here. There were no biocytinfilled neurons within the vocal motor circuit following labeling of trunk or fin muscles. Instead, biocytin-filled motoneurons were found within the ventral motor column in a pattern consistent with reports in midshipman and other teleosts using horseradish peroxidase (HRP) as a retrograde tracer (see Bass, 1985; Finger and Kalil, 1985); parallel experiments using dextran-biotin would be necessary to distinguish transneuronal labeling.

\section{Vocal circuit}

Following ipsilateral labeling of the sonic nerve, eight groups of biocytin-filled neurons were identified. The three groups of neurons at the level of the motor nucleus will first be presented followed by the five within the more rostral acoustic efferent and afferent nuclei. The extent and positions of each of these groups have been superimposed on a dorsal view of the brainstem in Figure $1 C$.

Motor nucleus. The midline pair of sonic motor nuclei extend from the caudal brainstem into the rostral spinal cord. The boundaries of the ovoid-shaped motor nuclei are well defined and the positions of motoneurons are always confined to within those boundaries (Bass, 1985; Bass and Baker, 1990). Biocytin labeling of a single sonic nerve resulted in bilateral labeling of sonic motoneurons (SMN, Figs. $2 A-D, 4 A-G$ ). Isolated, biocytin-filled fibers crossed the medial longitudinal fasciculus (MLF), which lies just ventral to the sonic motor nucleus, along the rostral-caudal extent of the sonic motor nuclei (Fig. 4D-G). In contrast, labeling of the sonic nerve with the high-molecularweight dextran-biotin resulted in labeling of only ipsilateral motoneuron axons and somata whose dendrites extended into the contralateral motor nucleus; no labeled fibers were found in the MLF (Fig. 2E,F).

Both biocytin and dextran-biotin labeling of the sonic nerve distinguished a rostral group of motoneurons whose ovoidshaped somata were about $50 \%$ smaller than the round-shaped motoneurons that predominated the remainder of the nucleus (Fig. $2 C, D, F$ ). In Figure 5, $A$ and $B$ are horizontal sections showing a pattern observed in 27 specimens where motoneurons were labeled bilaterally throughout the rostral-caudal extent of the nucleus. There was extensive crossing of fibers at the midline, 

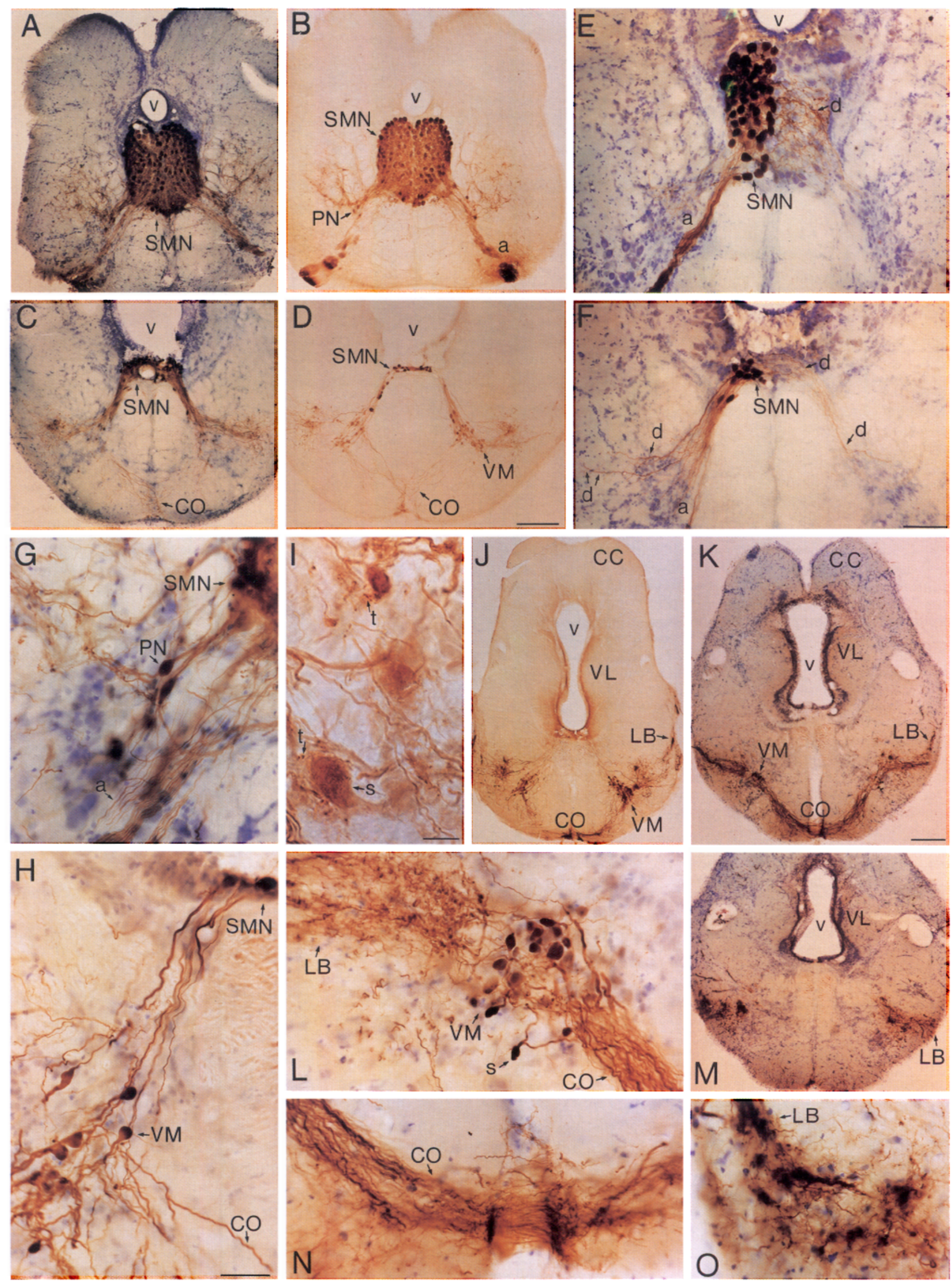

Figure 2. Color photomicrographs illustrating biocytin labeling of the vocal motor circuit at the level of the sonic motor nuclei. All sections, except $B, D, I$, and $J$, were counterstained with cresyl violet. Labeling of a single sonic nerve resulted in bilaterally labeled motoneurons throughout the caudal $(A, B)$-rostral $(C, D)$ extent of the sonic motor nuclei $(S M N)$. Dextran-biotin labeling of one sonic nerve resulted in only ipsilaterally filled motoneurons ( $E, F$; see Fig. $4 E, G$ for corresponding line drawings). Rostrally, motoneuron dendrites $(d, F)$ extend far lateral into the neuropil. 

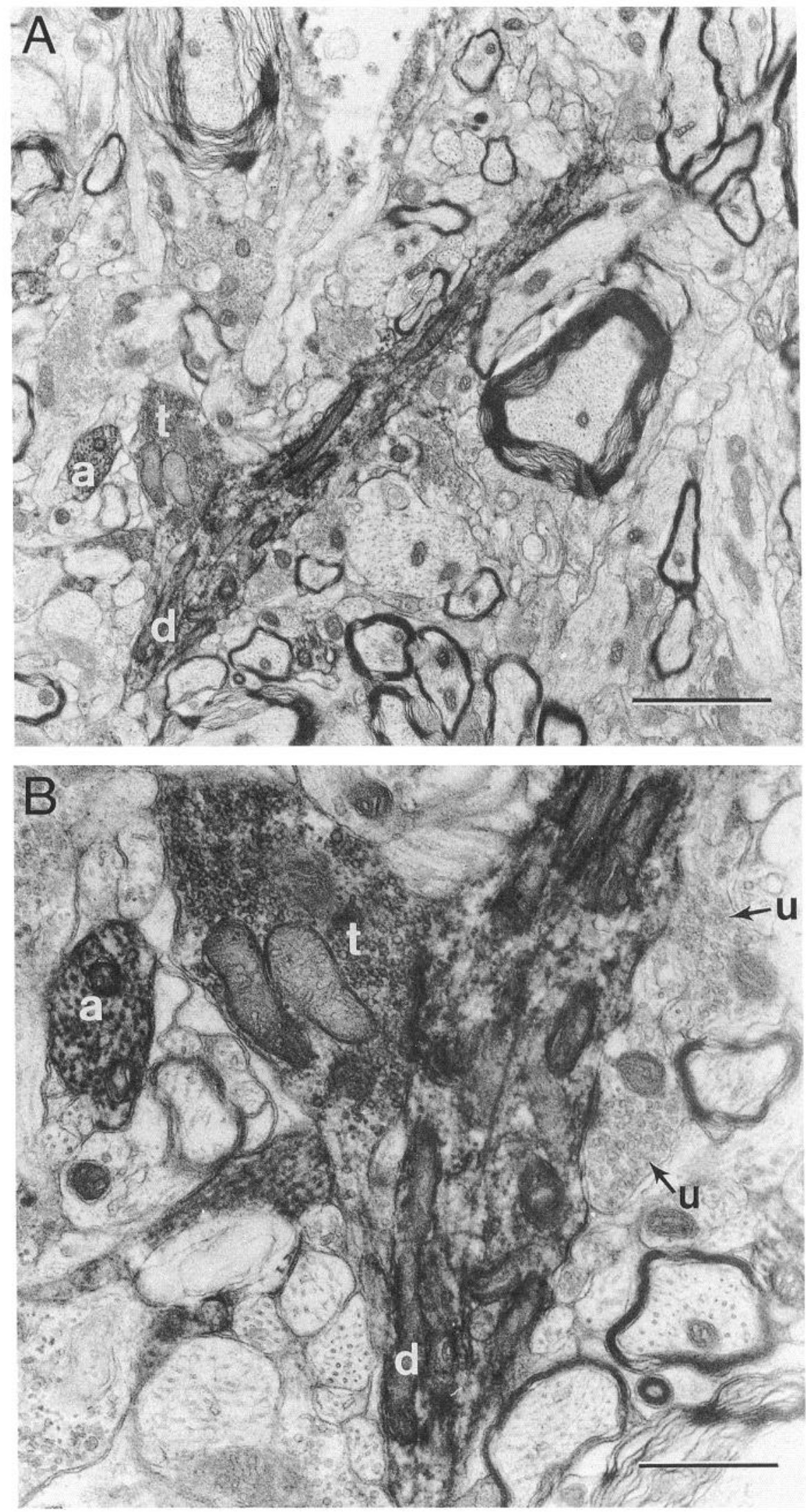

Figure 3. Ultrastructural localization of biocytin: low- $(A)$ and high- $(B)$ power electron micrographs of biocytin label from the region of the lateral brainstem bundle dorsolateral to the ventral medullary nucleus (compare Fig. $2 K$ ). A diffuse reaction product appeared within terminals, axons, and dendrites ( $t, a, d$, respectively for corresponding structures in $A, B)$. Synaptic vesicles within the labeled terminal $(t, B)$ were uniformly coated with the reaction product. Note absence of reaction product in other terminals with synaptic vesicles $(u)$ along the labeled dendrite, suggesting selectivity of transneuronal transport. Scale bars: $A, 2.0 \mu \mathrm{m} ; B, 0.8$ $\mu \mathrm{m}$.

Sonic motor axons $(a ; B, E)$ exit the nucleus ventrally. Biocytin-filled pacemaker neurons $(P N)$ are distributed along the ventrolateral margins of the sonic motor nuclei (e.g., $B, G$ ). At rostral levels, labeled fibers and somata continue ventrolaterally and give rise to a distinct group in the ventrolateral medulla ( $V M ; D, H, J-L$; see Fig. $4 G-I$ for line drawings). Biocytin-filled terminals $(t)$ are found near labeled pacemaker somata ( $s$, $I)$. VM fibers join ventral commissural $(C O ; J-L, N)$ and lateral brainstem $(L B ; J-M, O)$ fiber bundles. $C C$, cerebellar crest; $v$, fourth ventricle; $V L$, vagal lobe. Scale bars: $D, 200 \mu \mathrm{m}$ (for $A-D$ ); $F, 100 \mu \mathrm{m}$ (for $E, F$ ); $H, 50 \mu \mathrm{m}$ (for $G, H, L, N, O$ ); $I, 10 \mu \mathrm{m} ; K, 200 \mu \mathrm{m}$ (for $J, K, M$ ). 
Figure 4. Chartings of biocytin labeling of the motoneuron-pacemaker circuitry. Line drawings of sections show locations of biocytin-filled neurons and fibers after labeling of a single sonic nerve in a $12.7 \mathrm{~cm}$ female $(1 \mathrm{l} \mathrm{d}$ survival). The large dots in the sonic motor nucleus ( $S M N, A-G$ ) are motoneurons, while smaller dots along its ventrolateral margin are pacemaker neurons $(P N$, $A-F)$. At rostral levels, a dense cell group within the ventrolateral medulla (VM, $G-I)$ is continuous with extensive ventral commissural $(\mathrm{CO} ; \mathrm{H}, I)$ and lateral brainstem $(L B, I)$ bundles. Labeled motoneuron axons exit via the occipital nerve roots $(O C ; A, C) . C C$, cerebellar crest; $D R$, dorsal root; $F N$, funicular nuclei; $M L F$, medial longitudinal fasciculus; $S U$, supramedullary neurons; $s$, spinal canal; $v$, fourth ventricle; $V L$, vagal lobe; $X$, vagal nerve; $X m$, vagal motor nucleus. Each $50 \mu \mathrm{m}$ section is separated by $150 \mu \mathrm{m}$. Scale bar in $A$, $500 \mu \mathrm{m}$ (for $A-I)$.

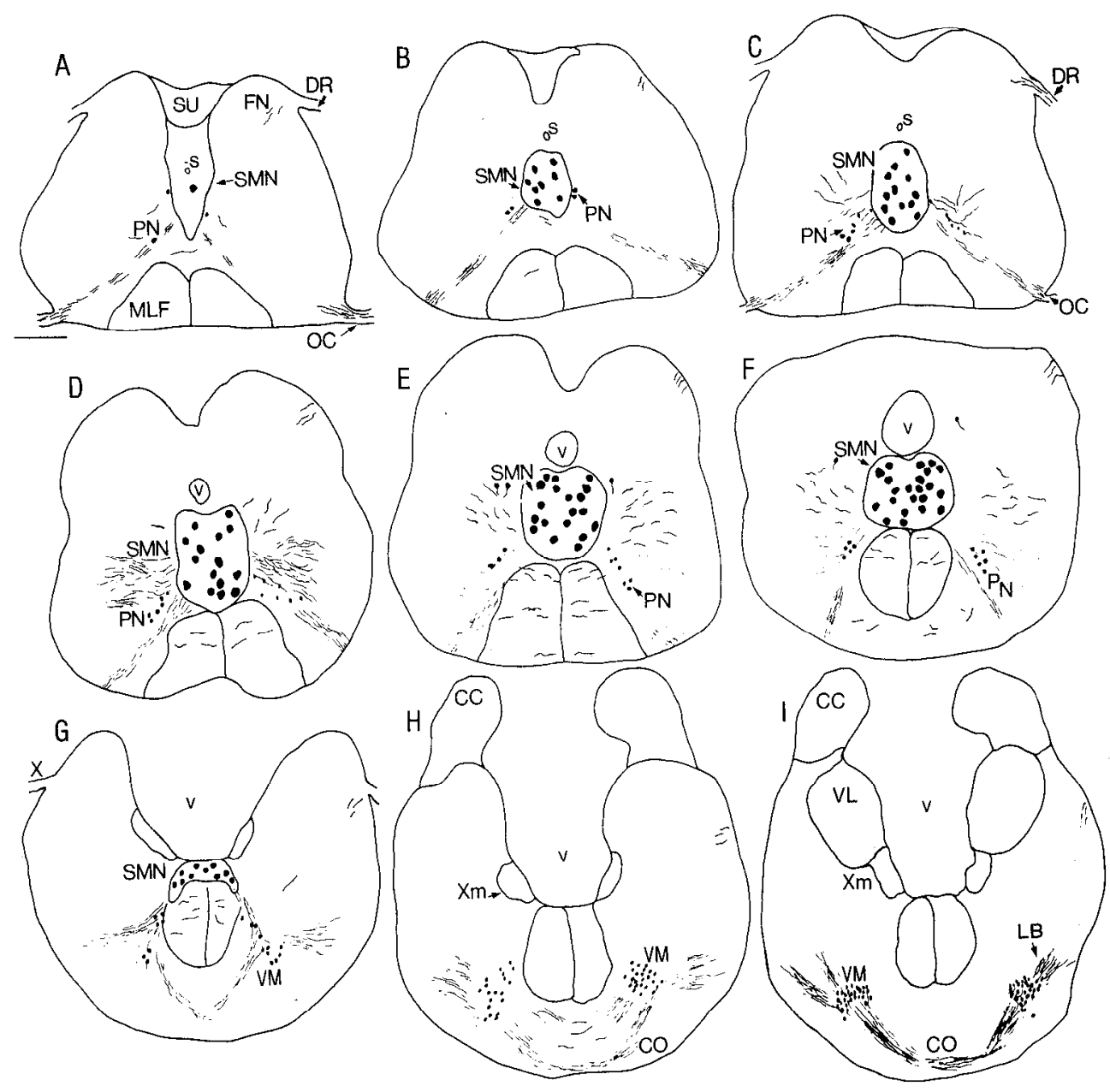

especially for the rostral population of smaller motoneurons (double arrows, Fig. 5B). Except for two juveniles with short survival times $(1,1.3 \mathrm{~d})$, bilateral filling of motoneurons was always associated with bilateral labeling of other nonmotoneurons that lie outside the boundaries of the sonic motor nuclei (see below).

In those cases with minimal biocytin transport, only the rostral cluster of motoneurons was consistently filled bilaterally with biocytin. In Figure 5, $C$ and $D$ are transverse sections showing a labeling pattern observed in 19 cases: motoneurons and their axons were labeled throughout the rostrocaudal extent of the ipsilateral nucleus. Motoneuron dendrites (d, Fig. $5 C$ ) ramified across the midline into the contralateral nucleus. Contralaterally, labeling was confined to the rostral cluster of smaller motoneurons where there was extensive crossing of fibers (Fig. $5 D$ ), as was seen in Figure 5, $A$ and $B$. In 4 of the 19 cases, there were also biocytin-filled nonmotoneurons.

Pacemaker neurons. The fusiform-shaped, biocytin-filled neurons identified as pacemaker neurons along the ventrolateral perimeter of the sonic motor nucleus (PN, Figs. $2 B, G ; 4 A-F$ ) were entirely similar in size, morphology, and position to individual, neurophysiologically identified, HRP-filled pacemaker neurons (Bass and Baker, 1990). Biocytin-filled terminals were found within the sonic motor nucleus and must largely represent the terminal boutons of pacemaker axons, while fibers that extended laterally along the sonic motor nucleus (e.g., Fig. $2 A, B, G)$ must be the lateral dendrites of pacemaker neurons (see
Bass and Baker, 1990, and Discussion). Some lateral dendrites, especially those at rostral levels (e.g., Fig. $2 C, D$ ), however, must be those of motoneurons since they were also labeled with dextran-biotin (d, Fig. $2 F$ ), which was not transported transneuronally. Biocytin-filled terminal boutons were also found outside of the sonic motor nucleus (e.g., Fig. $2 I$ ) and presumably originated from other biocytin-filled nonmotoneurons (see below). The latter may include labeled neurons infrequently found dorsolateral to the motor nucleus (Fig. $4 E, F$ ) in positions corresponding to tyrosine hydroxylase-positive neurons whose axons terminate extensively in the neuropil lateral to sonic motoneurons (Marchaterre et al., 1989).

Ventral medullary mucleus. At the far rostral level of the sonic motor nucleus, biocytin-filled neurons continued ventrolaterally amid exiting sonic motor axons and gave rise to a previously unrecognized, dense group of round to ovoid-shaped neurons within the ventrolateral medulla (VM, Figs. $2 D, H, J-L ; 4 G-I$ ). These neurons gave rise to an extensive, ventral commissural bundle (CO, Figs. $2 J-L, N ; 4 H, I$ ) continuous with their homonymous contralateral group, and an equally robust lateral bundle that linked the caudal brainstem to the rostral brainstcm (LB, Figs. $2 J-M, O ; 4 I$ ).

Statoacoustic efferent nucleus. The statoacoustic efferent nucleus was the first of the five groups of neurons at more rostral brainstem levels that contained biocytin-filled neurons (SE, Fig. $1 C$ ). Efferent neurons were identified here following selective biocytin labeling of the saccular or anterior branches of the 

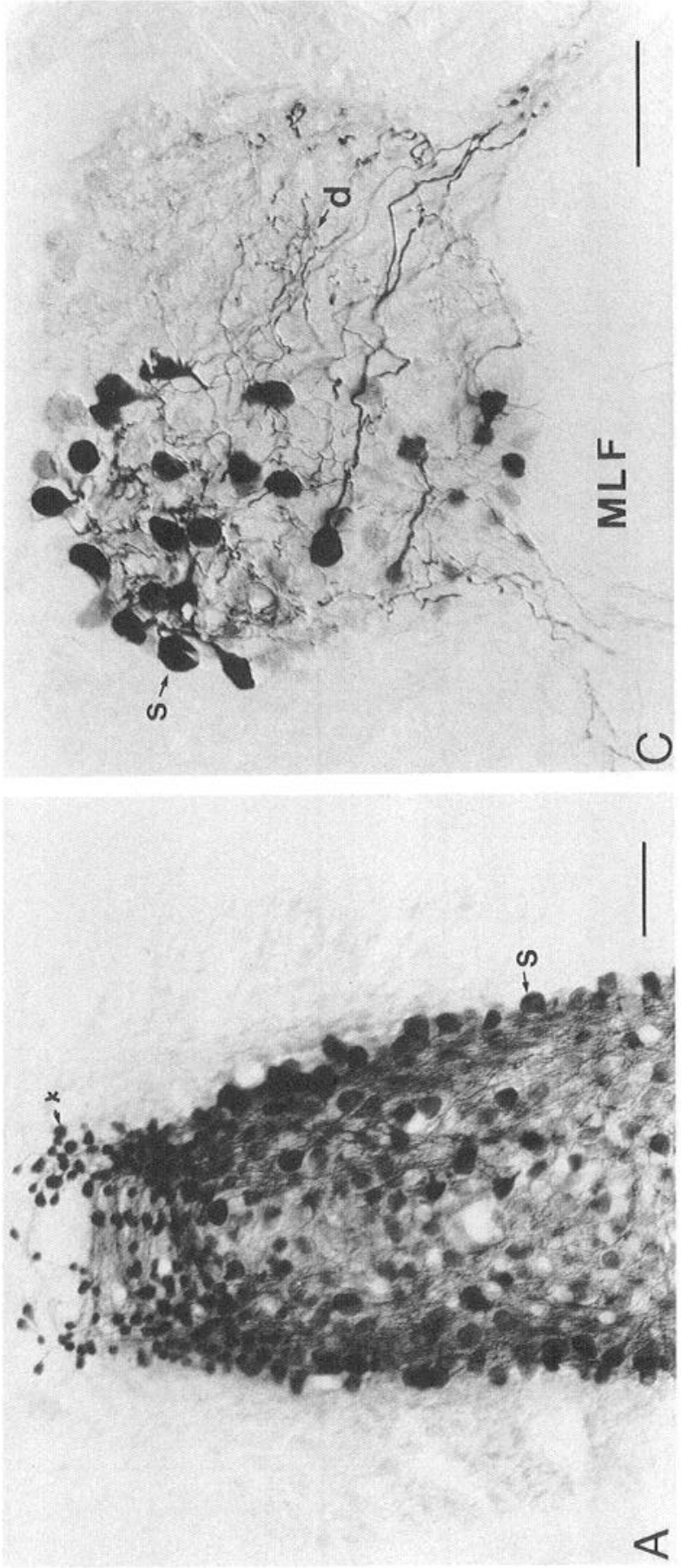
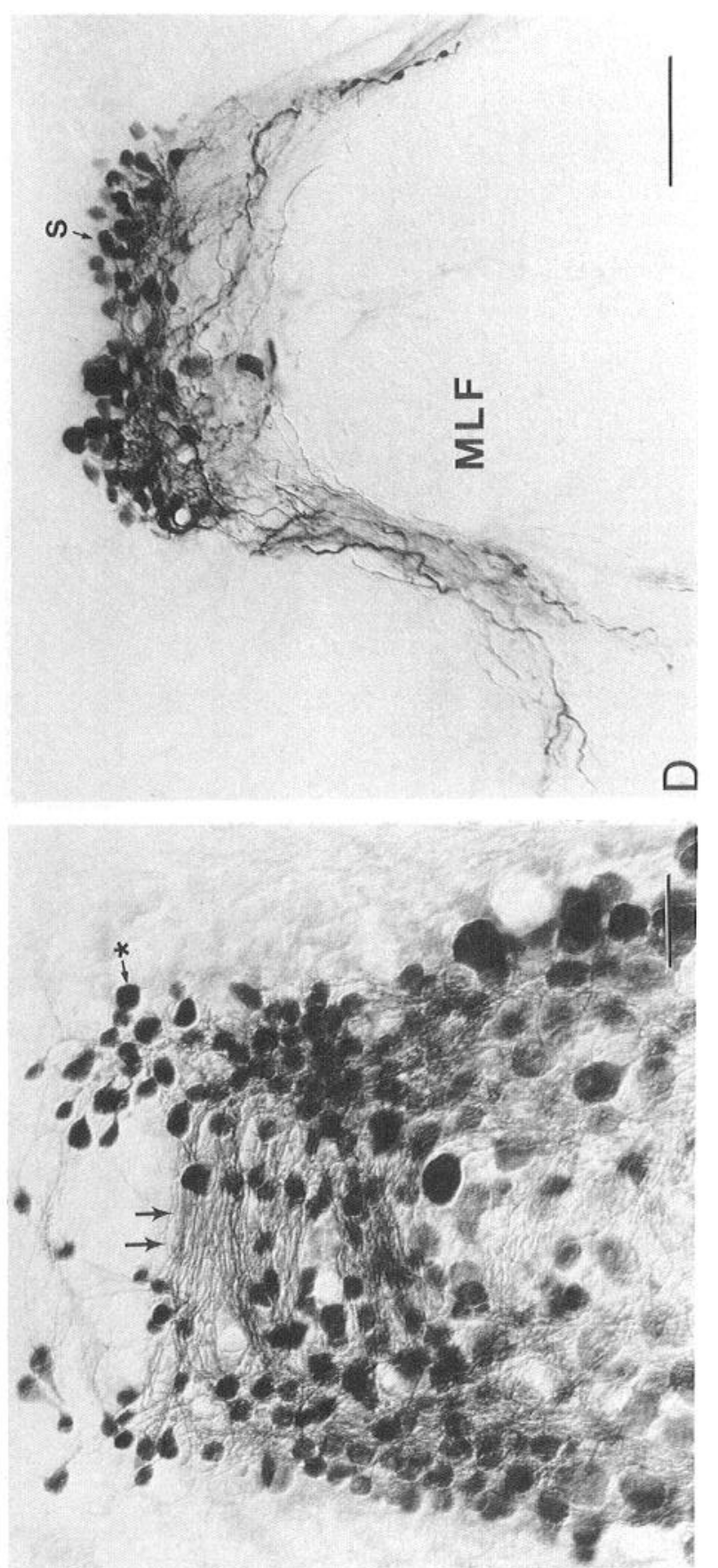

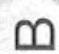

을. ․ㅗㄹ

空

an

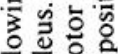

要要

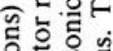

글

s.

둥

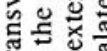

5

하의

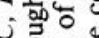

은

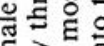

空

हू 댕을

굴

$\pi \%$

उ

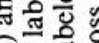

क의 은

तु

政

跣

응

동등

的跑

>융

믐

हึ。

응

통응응

$\circ \%$

๘

s

员

员

类

0.

. 5 क्ष

응잉

记

를 융

5

s.

은 즌

원

E잉

흠

为递 of

象告

政

요영

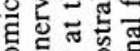

을중

क

的娄

댄

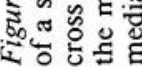


Figure 6. Chartings of biocytin labcling in the rostral, "acoustic" brainstem: line drawings of sections from a 12.3 $\mathrm{cm}$ male with labeling of a single sonic nerve ( $9 \mathrm{~d}$ survival). The lateral brainstem bundle $(L B, A)$ arising from the ventral medullary nucleus $(V M, A)$, passes ventral to medial and lateral divisions of the facial motor nucleus (VII; $B, C)$, and terminates on the dendrites and somata of a caudal division of the statoacoustic efferent nucleus $(S E, C)$. The lateral bundle continues rostral $(D)$ and biocytin-filled neurons are found in dorsal and ventral tegmental groups $(D T$ and $V T$, respectively; $E, F)$ that are adjacent to or within descending $(D O)$ and magnocellular $(M)$ octaval nuclei. Commissural fibers $(C O, F)$ are continuous with DT neurons across the midline. $A n$, anterior lateral line nerve; $C C$, cerebellar crest; $C g$, granule cell layer of cerebellum; $\mathrm{Cm}$, molecular layer of cerebellum; $M L F$, medial longitudinal fasciculus; $M N$, medial octaval nucleus; $P l l n$, posterior lateral line nerve; $P O$, posterior octaval nucleus; $T$, nucleus tangentialis; $v$, fourth ventricle; $V d$, descending tract of the trigeminal nerve; $V I$, abducens nucleus; VIIn, seventh cranial nerve; VIIIn, eighth cranial nerve; $I X n$, ninth cranial nerve. Distance between each $50 \mu \mathrm{m}$ section is, $A-B, 400 \mu \mathrm{m} ; B-C, C-D, 350 \mu \mathrm{m} ; D-$ $E, E-F, 200 \mu \mathrm{m}$. Scale bar in $A, 500$ $\mu \mathrm{m}$ (for $A-I$ ).
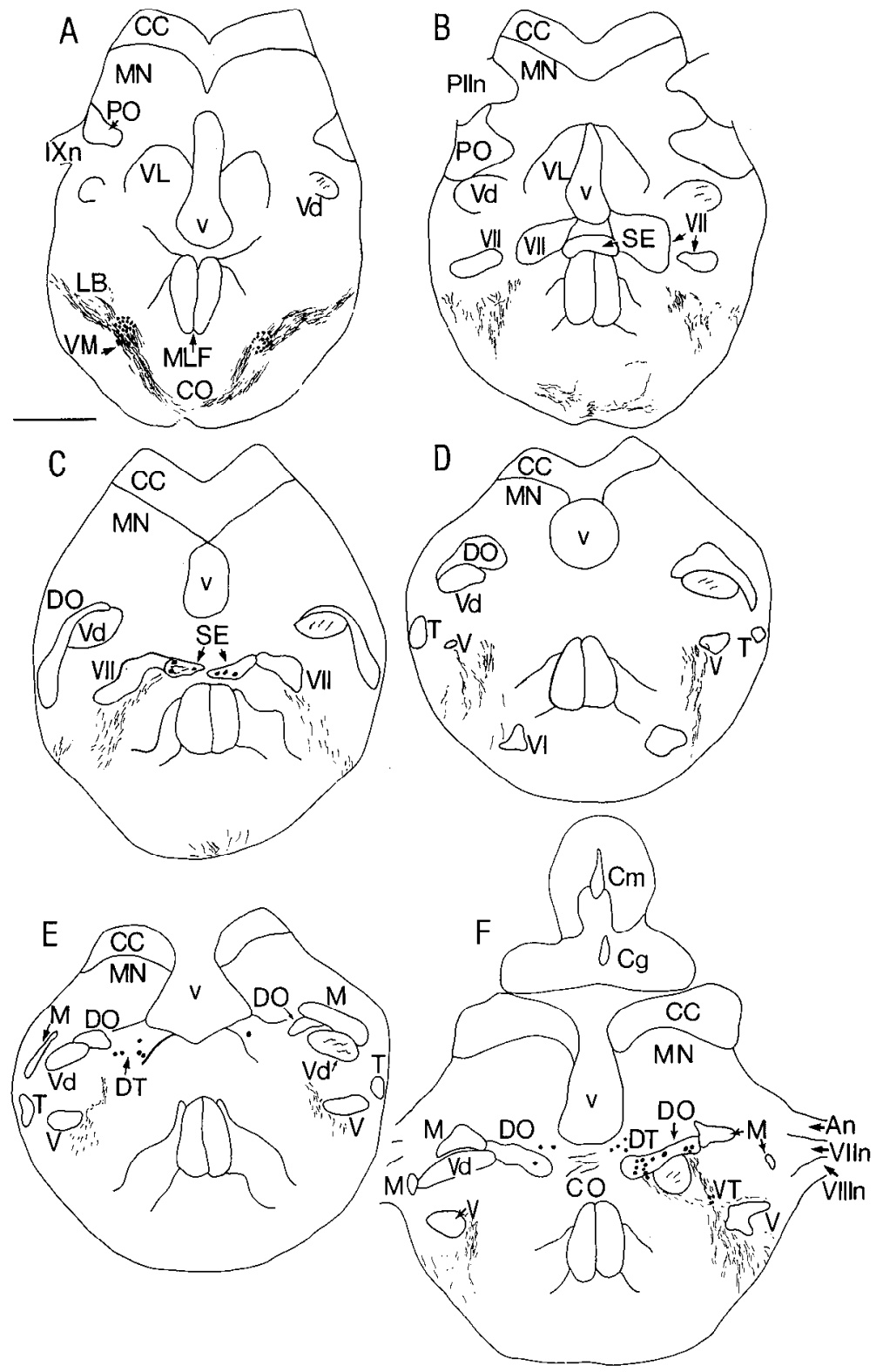

eighth nerve (see below). The efferent nucleus had rostral and caudal divisions (Fig. 6, $B$ and $C$, respectively) separated by internal arcuate fibers. Following biocytin labeling of the sonic nerve, filled terminals were positioned along the dendrites and somata of efferent neurons that themselves were lightly stained, lacking the Golgi-like, intense filling characteristic of all other biocytin-labeled neurons (Fig. 7A-D). The labeled somata were found within the caudal division of the efferent nucleus (Fig. $6 C)$ and corresponded to a dorsal subgroup in the closely related toadfish where individual neurons were identified physiologi-

Figure 7. Color photomicrographs illustrating biocytin labeling of the vocal motor circuit at the level of acoustic efferent and afferent nuclei. Ali sections, except $A, B, I$, and $J$, were counterstained with cresyl violet. Labeling of a single sonic nerve resulted in bilaterally labeled neurons throughout the rostral brainstem. Biocytin-filled fibers terminate on lateral dendrites $(d, A)$ that originate from neurons of the statoacoustic efferent nucleus ( $S E, A$; see Fig. $6 C$ for corresponding line drawing). SE neurons are lightly filled with biocytin; terminals $(t, B-D)$ are positioned on both dendrites and somata. Asterisks in $C$ and $D$ point to corresponding positions. Biocytin-filled neurons are also found in a ventrolateral subgroup of the efferent nucleus $(E)$; its neurons are also covered by biocytin-filled terminals (inset, $E$ ). Rostral to the efferent nucleus, a ventral tegmental group $(V T, F)$ of round-shaped neurons is medial to a caudal division of the trigeminal motor nucleus ( $V, F$; see Fig. $6 F$ for line drawing). The photomicrograph in the inset of $F$ is at the same level, but from a section not counterstained with cresyl violet. Ventral tegmental neurons are embedded in densely staining fibers and terminals $(G, H)$. A dorsal tegmental group $(D T, F)$ includes smaller, fusiform-shaped somata $(I-K)$, also surrounded by fibers and terminals. Dorsal tegmental neurons extend to the ventricular cell layer $(V C)$ and are positioned within or around the medial aspect of the descending octaval nucleus $(D O ; K$ and $L$, which are, respectively, from right and left sides of the brain). A hindbrain paraventricular group of biocytin-filled neurons $(M)$ lies medial to the anterior octaval nucleus; its somata are also positioned close to the ventricular 

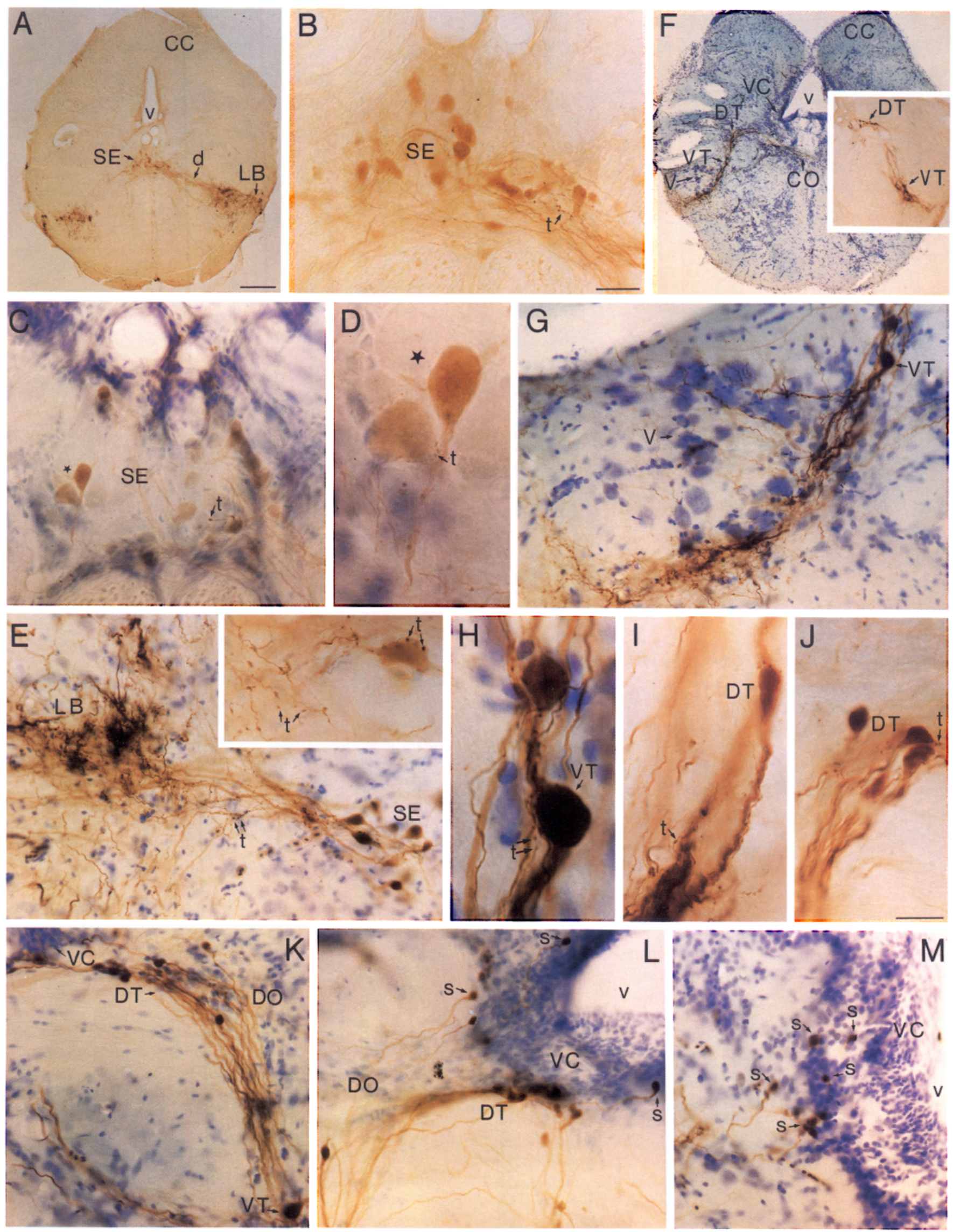

cell layer (see Fig. $8 B$ for line drawing). $C C$, cerebellar crest; $v$, fourth ventricle. Scale bars: $A, 200 \mu \mathrm{m}$ (for $A, F$ ); $B, 50 \mu \mathrm{m}$ (for $B, C, E, G, K-M$ ) $J, 20 \mu \mathrm{m}$ (for $D, E$ inset, $H-J$ ). 
Figure 8. Line drawings of sections from a $10.4 \mathrm{~cm}$ female ( $6 \mathrm{~d}$ survival) following labeling of a single sonic nerve that resulted in biocytin-filled neurons and fibers as far rostral as the midbrain. The lateral brainstem bundle $(L B, A)$ is continuous with a hindbrain paraventricular group $(I I P, B)$ of biocytin-filled neurons along the ventricular cell layer $(V C)$, medial to a rostral segment of the anterior octaval nucleus $(A O)$. Labeled fibers continue rostral and terminate along the ventromedial aspect of the anterior eminentia granularis $(E G, C$; broken lines indicate torn edge of section). Biocytin-filled fibers terminate in a midbrain isthmal nucleus $(I s, D)$. An isthmal paraventricular group $(I P)$ of biocytin-filled neurons is located along the ventricular cell layer $(D, E) . C C$, cerebellar crest; $C g$, granule cell layer of corpus of cerebellum; $\mathrm{Cm}$, molccular layer of corpus; $L L$, lateral lemniscus; $L V$, nucleus lateralis valvulae; $M L F$, medial longitudinal fasciculus; $T e$, midbrain tectum; $O C$, oculomotor complex; $T S$, torus semicircularis, $v$, fourth ventricle; $V g$, granule cell layer of valvula; $V \mathrm{~m}$, molecular layer of valvula; $V n$, trigeminal nerve. Distance between each $50 \mu \mathrm{m}$ section is $150 \mu \mathrm{m}$. Scale bar in $A, 500 \mu \mathrm{m}$ (for $A-E$ ).
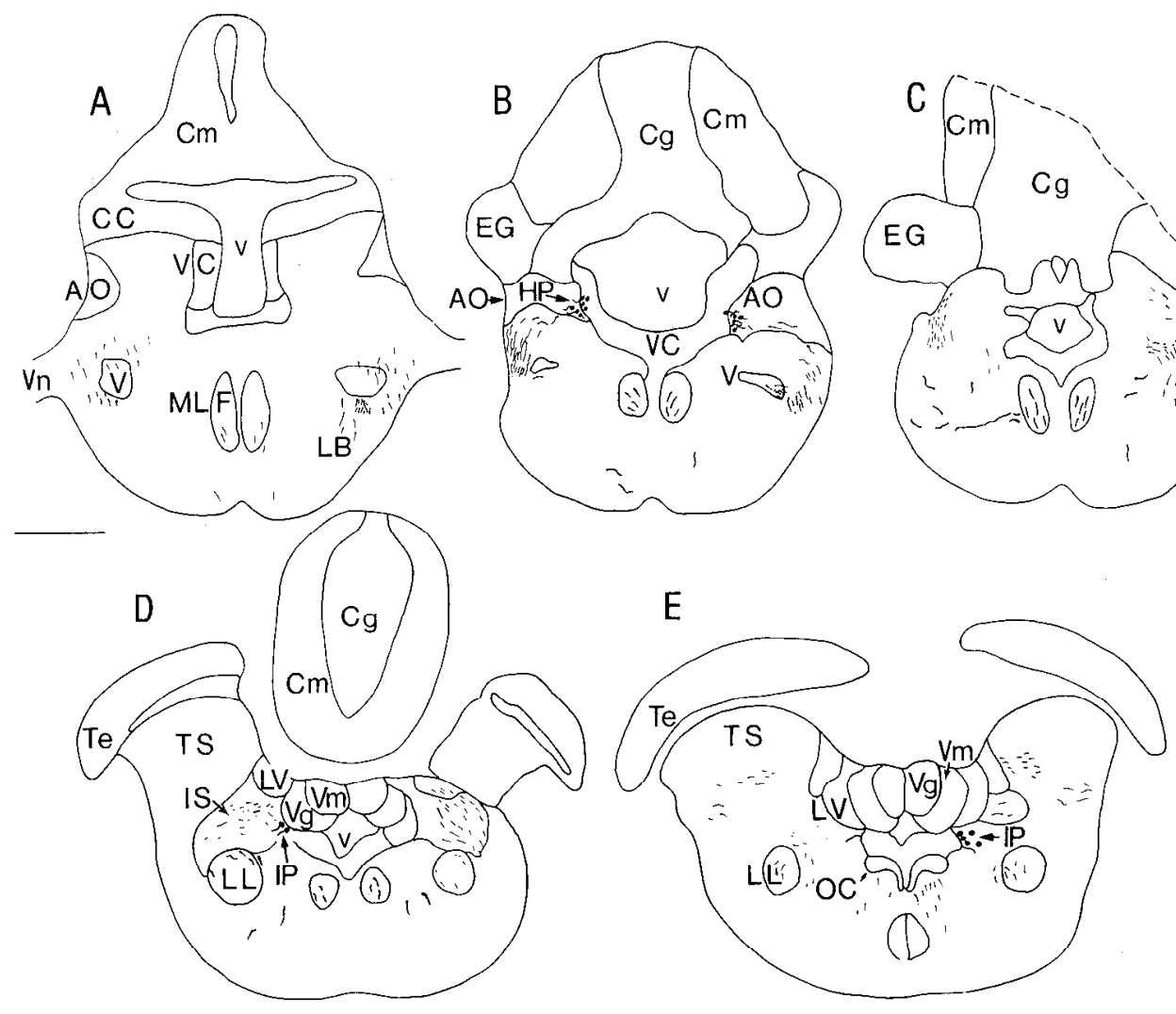

cally and anatomically as projecting mainly to the sacculus (Highstein and Baker, 1986). After sonic or eighth nerve labeling, biocytin-filled neurons were also found within a ventrolateral subgroup of the efferent nucleus that also had terminals covering their somata (SE, Fig. $7 E$ ).

The lateral bundle extended ventral to all divisions of the facial motor nucleus (VII, Fig. $6 B, C$ ) and continued farther rostrally to surround the ventromedial aspect of a caudal division of the trigeminal motor nucleus (V, Figs. $6 D-F, 7 F$ ). Biocytin-filled terminals were diffusely scattered over somata within the facial and trigeminal motor nuclei.

Statoacoustic afferent nuclei. As the lateral bundle continued along the lateral brainstem, it joined two groups of densely filled neurons at the level of eighth nerve-recipient, octaval nuclei. A ventral tegmental group (VT) of round-shaped cells was ventromedial to the descending (DO) and magnocellular (M) octaval nuclei (Figs. $6 F, 7 F-H$ ). The ventral tegmental neurons formed a continuum with a second, dorsal tegmental (DT) group of smaller, round or fusiform-shaped cells positioned within and around the dorsomedial aspect of the descending nucleus (Figs. $6 E, F ; 7 F, I, J$. Dorsal tegmental neurons extended dorsally up to the ventricular cell layer (VC, Fig. $7 K, L$ ) and slightly farther rostral than ventral tegmental neurons. Labeled fibers from the tegmental groups crossed the midline among internal arcuate fibers and were continuous with the homonymous, contralateral neurons (CO, Figs. $6 F, 7 F$ ). This site was the second major crossing of biocytin-labeled fibers rostral to the sonic motor nucleus, although the bundle was not nearly as dense as that joining the more caudal, ventral medullary neurons. Although labeled terminal boutons were scattered throughout the octaval region, they were concentrated over nucleus magnocellularis and the tegmental groups (Fig. $7 H-J$ ). Labeled terminals were also found within a rostral division of the trigeminal motor nucleus (V, Fig. $8 A, B$ ).

Rostral to the entrance of the trigeminal nerve, a fourth, hindbrain paraventricular group (HP) of small, spherical-shaped, biocytin-filled neurons was also located along the ventricular cell layer, medial to the anterior octaval nucleus (Figs. $7 M, 8 B$ ). Biocytin-filled fibers from this cluster streamed ventrolaterally to join the lateral bundle. Farther rostral, a densc ficld of terminal boutons was coincident with the lateral bundle up to and including the most ventral granule cells of the cerebellum's eminentia granularis (EG, Figs. $8 C, 9 A, B$; for cerebellar terminology, see Bass, 1982).

As the lateral bundle continued into the midbrain, faintly staining fibers and terminals were found in an isthmal nucleus (Is) of small, round cells (Figs. $8 D, 9 C$ ) positioned between the torus semicircularis (TS, Fig. $8 D$ ) and the lateral lemniscus (LL, Fig. $8 D$ ). A fifth, isthmal paraventricular group (IP) of biocytinfilled neurons was also found along the ventricular cell layer (Figs. $8 D, E ; 9 D$ ). Their fibers, like those of the hindbrain paraventricular group, extended ventrolateral and joined the lateral bundle. Labeled fibers were also located in and around the lateral lemniscus, and in the torus semicircularis (Fig. $8 D, E$ ).

Dorsal root afferents. In many cases, dorsal root afferents at the level of the sonic motor nucleus ipsilateral to the injection site contained biocytin-filled fibers that terminated in the funicular nuclei (Fig. 4). These afferents were never found to terminate in any of the vocal motor or acoustic nuclei identified here. Labeled fibers continued rostrally in the descending tract of the trigeminal and terminated medial to the tract, just rostral to the dorsal and ventral tegmental groups of biocytin-filled neurons (Fig. 6). Inputs to the funicular nuclei were also seen in specimens with biocytin labeling of the trunk, fin, or head 
muscles. Dorsal root afferents were $n o t$ labeled in dextran-biotin preparations, suggesting a lack of transport across ganglion cells. The source of the biocytin-labeled afferents has not yet been specified.

\section{Eighth nerve labeling}

The labeling pattern of biocytin-filled, octaval afferents (Fig. $9 E-G, I, J)$ resembled that reported in the closely related toadfish (Highstein et al., 1992). Afferents from the saccular branch of the eighth nerve were densely labeled throughout the octaval cell column (e.g., AO, DO; Fig. $9 F, G, I, J)$ and the eminentia granularis (EG, Fig. 9E). A separate report will describe the central projections of each of the octaval end organs; only those results pertinent to the present study are focused upon here. Thesc results also indicated that transneuronal transfer of biocytin was possible after labeling of a sensory, for example, eighth, nerve. Thus, biocytin transfer across neuronal groups was not limited to a motor, for example, sonic, nerve innervating skeletal muscle.

Biocytin-filled neurons were found at five principal sites. The first site was the statoacoustic efferent nucleus that was also labeled transneuronally via the sonic nerve. Efferent neurons had an expansive dendritic tree (SE, Fig. 9I-K). Their axons (a, Fig. $9 G-I)$, as their dendrites and somata, were densely filled with biocytin after saccular, but not sonic, nerve labeling. The lateral brainstem bundle labeled transneuronally from the sonic nerve completely overlapped the anterior-posterior and mediallateral extent of the efferent neurons' dendrites, which extended to the subpial edge of the ventrolateral brainstem (compare Figs. $7 A$ and $9 J, K$ ). The efferent nucleus described here is the only known brainstem source of direct innervation of the inner ear of teleosts (review: Roberts and Meredith, 1992). Thus, the remaining biocytin-filled neurons within the octaval complex were likely labeled via transneuronal coupling. This clearly included the dorsal and ventral tegmental groups (DT, VT; Fig. $9 L$ ) that were also labeled transneuronally via the sonic nerve. A fourth, large cluster of biocytin-filled neurons were found dorsomedially along the midline, immediately caudal to the dorsal and ventral tegmental neurons, in an area that has been compared to the superior olivary complex of tetrapods ( $\mathrm{SO}$, Fig. $9 H$; see Discussion). The fifth group was a dense cluster of round neurons lateral to the ventral medullary nucleus (VM, also labeled by the sonic nerve), where a few neurons were also filled (Fig. 9M).

\section{Discussion}

\section{Biocytin method}

Tritiated amino acids, wheat germ agglutinin (WGA), WGA conjugated to HRP, and fragment $C$ of tetanus toxin have all been used as transneuronal tracers in vertebrates (e.g., Wiesel et al., 1974; Baker and Spencer, 1986; Evinger and Erichsen, 1986; Collins et al., 1991). In these cases, transneuronal labeling appears to involve transport across a single central synapse. Transneuronal transport of herpes simplex virus type 1 is rcported across multiple synaptic levels, but its use is apparently restricted to mammals (cf. Hoover and Strick, 1993). Horikawa and Armstrong (1988) first described the use of biocytin as an intracellular dye to reveal the complete morphology of single neurons in explant cultures of the supraoptic nucleus of rats. Both biocytin and Neurobiotin (biotinamide), another derivative of biotin, have also been utilized for anterograde and retrograde tracing in mammalian brain (King et al., 1989; Izzo,
1991; Lapper and Bolam, 1991; McDonald, 1992). When retrograde transport provided a Golgi-like filling of neurons, it seemed to depend on large injections or axonal damage. In concordance with this observation, the most extensive retrograde (and transneuronal) transport of biocytin (or Neurobiotin) in midshipman occurs when the sonic nerve is cut and crystals are directly applied.

The extensive transneuronal transport of biocytin reported here for the vocal motor system may depend in large part on neuronal coupling via gap junctions. A previous electron microscopic study of the midshipman's sonic motor nucleus identified both axosomatic and axodendritic, morphologically mixed synapses with gap junctions adjacent to active zones usually associated with pleomorphic vesicles (Bass and Marchaterre, 1989). As Horikawa and Armstrong (1988) pointed out, biocytin is small enough to pass through gap junctions. Vaney (1991) injected biocytin or Neurobiotin into amacrine, horizontal, or ganglion cells of isolated cat or rabbit retinas and reported extensive tracer coupling between similar and different cell types. Thus, the most parsimonious interpretation is that intercellular transfer of biocytin is via gap junctions. As yet, information is not available as to the prevalence of gap junctions at sites other than the motor nucleus within the vocal-acoustic circuit identified here. An alternative or adjunct mechanism providing extensive neuronal coupling could be via a specific biocytin uptake mechanism at synaptic recognition sites (see also McDonald, 1992).

\section{Vocal motor circuit}

A number of pieces of evidence corroborate our contention here that the transneuronal biocytin transport we observed is specific to a vocal-acoustic circuit. This includes biocytin filling from the sonic nerve of (1) only contralateral sonic motoneurons and not other motoneurons in the vicinity of the sonic motor nucleus (see Bass, 1985); (2) neurons entirely similar in appearance and location to pacemaker neurons that were individually characterized neurophysiologically and anatomically as being the major, if not the only, source of direct synaptic input onto sonic motoneurons (Bass and Baker, 1990); (3) statoacoustic efferent neurons, also shown with intracellular methods to mainly innervate the sacculus (Highstein and Baker, 1986); and (4) neurons, fibers, and terminals in brainstem regions considered to be acoustic in teleosts (review: McCormick, 1992). Biocytin labeling of the saccular branch of the eighth nerve also produced filling of neurons filled via the sonic nerve as well, further suggesting a vocal-acoustic circuit.

The "large" biocytin-filled motoneurons identified in this study are equivalent to those described previously with intracellular staining and recording as having dendrites that branch bilaterally throughout the sonic motor nuclei and a single, unbranched axon that enters the ipsilateral sonic nerve (Bass and Baker, 1990). The functional attributes of the rostral cluster of smaller neurons within the sonic motor nucleus await analysis. Our data suggest these are motoneurons given that only small and large neurons were filled ipsilaterally within the sonic motor nucleus after dextran-biotin labeling of the sonic nerve, for which there was no evidence of transneuronal transfer. An earlier HRP study noted a light, granule-like precipitate in the somata of small neurons at the rostral pole of the sonic motor nucleus (Bass, 1985), which correspond to the small, biocytin and dextran-biotin filled neurons described here.

All biocytin-filled neurons, except those of the statoacoustic 

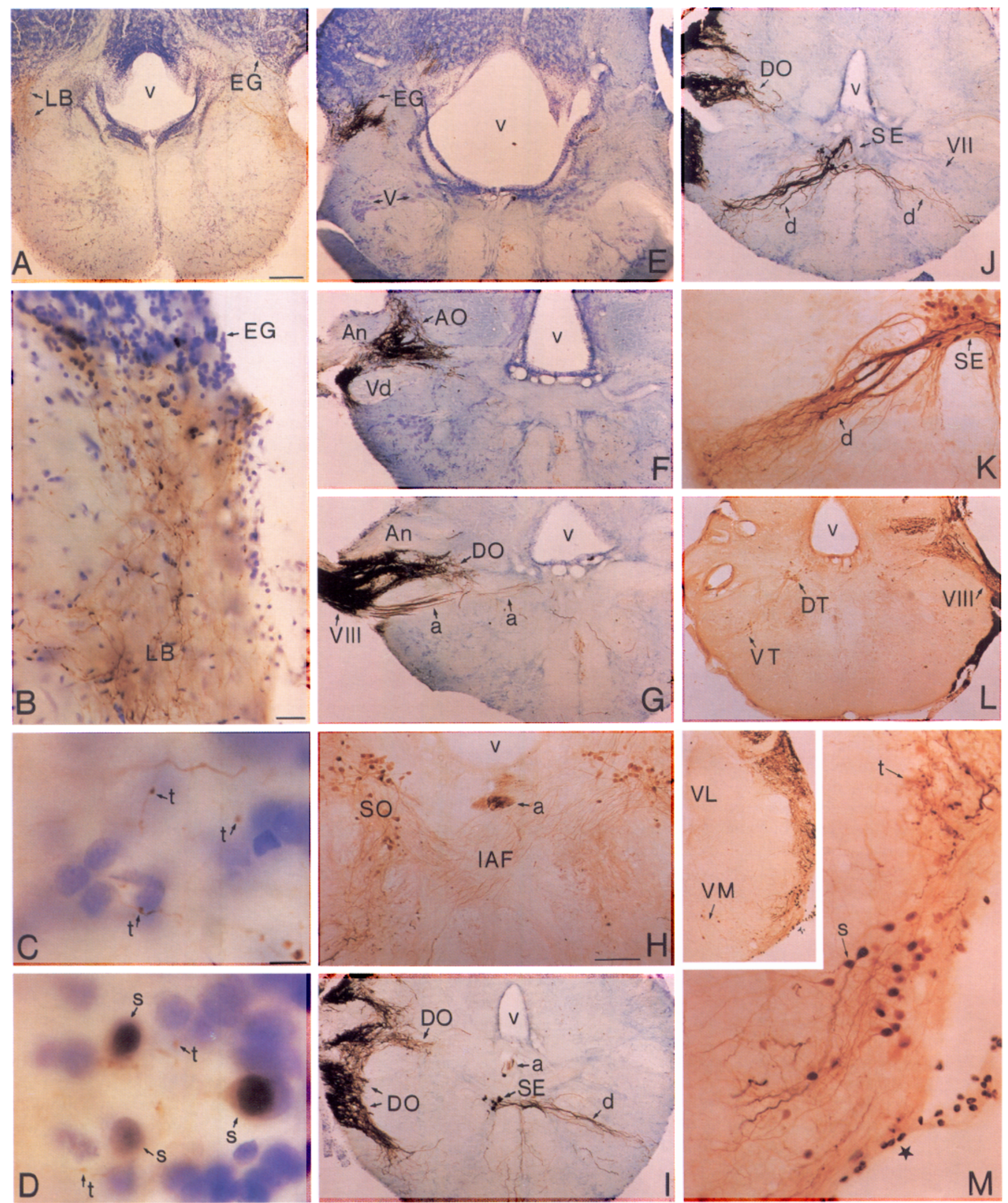

Figure 9. Color photomicrographs illustrating biocytin-filled neurons and fibers at the level of the cerebellum following labeling of a single sonic nerve $(A-D)$, and throughout the rostral brainstem after labeling of the eighth nerve $(E-M)$. All sections, except $H$ and $K-M$, are counterstained with cresyl violet. After labeling a single sonic nerve, the lateral brainstem bundle $(L B)$ extends rostrally to anterior levels of the eminentia granularis $(E G, A)$, where it terminates ( $B$; see Fig. $8 C$ for corresponding line drawing). Farther anterior, the lateral bundle terminates $(t)$ in a midbrain isthmal nucleus $(C)$; spherical-shaped, biocytin-filled somata $(s)$ lie along the ventricular cell layer $(D$; see Fig. $8 D$ for line drawing). Biocytin labeling of 
efferent nucleus, had a Golgi-like appearance characteristic of biocytin or Neurobiotin retrogradely filled motoneurons and nonmotoneurons, and neurons close to central injection sites (Izzo, 1991; Huang et al., 1992; Lapper and Bolam, 1992; McDonald, 1992; present results). Transneuronal retrograde transport has apparently occurred at synaptic sites across a minimum of three serially arranged, neuronal groups. The first site would be from ipsilateral motoneurons to pacemaker neurons bilaterally, which is consistent with extensive intracellular studics in both midshipman and toadfish. These studies demonstrate that pacemaker neurons are the only physiologically identified afferents to motoneurons and that individual pacemaker neurons densely innervate both motor nuclei (Pappas and Bennett, 1966; Bennett et al., 1985; Weiser et al., 1985; Bass and Baker, 1990). HRP-filled pacemaker axons ramify among the somata of both large and small motoneurons (Bass and Baker, 1990, unpublished observations), so both populations are likely sites of biocytin uptake. The second retrograde site would be from pacemaker neurons to the ventral medullary nucleus. The ventral medullary nucleus has not been identified as afferent to sonic motoneurons (Bass and Baker, 1990); its only possible retrograde source of biocytin would therefore be from pacemaker neurons. The third transneuronal site would occur between the ventral medullary nucleus and neurons of the rostral medulla (dorsal tegmental, ventral tegmental, and hindbrain paraventricular groups) and caudal midbrain (isthmal paraventricular group). All of these structures are likely to be interconnected in a manner more complex than that outlined above, for example, dorsal tegmental, hindbrain paraventricular, and midbrain isthmal neurons all converging onto ventral tegmental neurons, which in turn project to ventral medullary neurons. The biocytin method has allowed us to identify at least some components of this circuitry, and thus we are now in a position to cxplore it explicitly using single-cell recording and staining methods.

Two additional sites of transneuronal transfer of biocytin are likely via an anterograde transport mechanism. The first site would be from pacemaker afferents to contralateral motoneurons. As noted above, intracellular studies have demonstrated that single pacemaker axons terminate densely within both sonic motor nuclei (Bass and Baker, 1990). The second site of anterograde transport would be from one or more sources of biocytin-filled neurons onto the statoacoustic efferent neurons whose somata and dendrites were only lightly filled with biocytin. Similarly, Huang et al. (1992) reported anterograde transneuronal transfer of Neurobiotin from prefrontal cortex to neostriatum, which resulted in labeling of only the somata and primary dendrites of neostriatal cells positioned within areas of dense afferent fiber labeling.

\section{Acoustic circuit}

Several studies in teleosts suggest that dorsal and medial regions of the rostral brainstem that receive saccular inputs are acoustic in function (McCormick, 1992). The results of an HRP lracttracing study in toadfish (Highstein et al., 1992), and now this biocytin study in midshipman, are consistent with this hypothesis. HRP or biocytin labeling of the expected efferent octaval neurons was also observed in both investigations. In addition, biocytin labeling in midshipman resulted in the filling of an antero-postero column of neurons that lies largely medial to the descending octaval nucleus. The caudal neurons of this column, designated the superior olive, are comparable to the superior olive of other teleosts on the basis of topographical position and connectivity with the torus semicircularis, the midbrain auditory center that is homologous to the inferior colliculus (Echteler, 1984; McCormick, 1992; McCormick et al., 1992; McCormick and Braford, 1993). The dorsal and ventral tegmental groups, which make up the rostral portion of this column, together occupy roughly the same mediolateral position as the superior olive. The most caudally located biocytin-filled neurons positioned lateral to the ventral medullary nucleus (Fig. $9 M$ ) have not been previously reported in connectional studies of the teleost acoustic system. Like the dorsal and ventral tegmental groups, they may represent neurons that are specific to batrachoidids, or teleosts in general, that actively vocalize and are thus important loci of vocal-acoustic linkages.

\section{Descending vocal motor pathway and an acoustic link}

The network identified here using biocytin as a transneuronal tracer must represent the basis for the descending motor pathway that activates the vocal pacemaker circuit. The positions of many, if not all, of the biocytin-filled neurons in the rostral medulla (hindbrain paraventricular, dorsal, and ventral tegmental groups) and the midbrain isthmal region correspond to low-threshold, brain stimulation sites for eliciting sound in toadfish and midshipman (Demski and Gerald, 1974; Finc, 1979; Bass and Baker, 1990, 1991). The functional role of each of these neuronal groups in determining the temporal and spectral properties of vocalizations can now be addressed with singlecell recording techniques.

A linkage between the vocal motor circuit and the acoustic system has been suspected, but its demonstration has been far beyond that available with current mapping techniques. Four populations of neurons were labeled following biocytin labeling of either the saccular or sonic motor nerve: the efferent octaval nucleus, the dorsal and ventral tegmental nuclei, and the ventral medullary nucleus. The large group of small, round neurons lateral to the ventral medullary nucleus might also be included in this network; biocytin-filled neurons were scattered in this region in some of the specimens with sonic nerve labeling. Together, these neurons likely form a complex circuitry linking primary and higher-order acoustic nuclei of the midbrain and rostral medulla with the more caudal, vocal motor system. This circuit could be the basis for acoustically evoked vocalizations (review: Fine et al., 1977) and a vocal-related, corollary dis-

\footnotetext{
the saccular branch of the eighth nerve (VIII) demonstrates dense inputs to the medulla at the level of the anterior eminentia granularis $(E)$, anterior $(A O, F)$ and descending $(D O ; G, I, J)$ octaval nuclei. The dendrites $(d)$ of biocytin-filled somata in the statoacoustic eflerent nucleus $(S E, I-K)$ have a far lateral and rostral-caudal extent along the lateral brainstem within the trajectory of the lateral brainsten bundle labeled from the sonic nerve (see Fig. $7 A$ ). Statoacoustic efferent nucleus axons $(a)$ extend dorsally $(H, I)$, and eventually join the eighth nerve $(G)$. After labeling of the eighth nerve, biocytin-filled neurons are also positioned within the dorsal and ventral tegmental groups $(D T, V T ; L)$ and lateral to the ventral medullary nucleus [ $V M, M$; inset is low-power view showing positions of labeled somata $(s)$, and terminals $(t)$; asterisks represent corresponding positions]. For illustrative purposes, the photomicrographs in $H$ and $K-M$ are of unstained sections from a case where the anterior branch of the eighth nerve was labeled (results are entirely consistent with labeling of the saccular branch alone). $A n$, anterior lateral line nerve; $v$, fourth ventricle; $V L$, vagal lobe. Scale bars: $A, 200 \mu \mathrm{m}$ (for $A, E-G, I, J, L$ ); $B, 25 \mu \mathrm{m}$ (for $B, M$ ); $C, 10 \mu \mathrm{m}$ (for $C, D$ ); $H, 100 \mu \mathrm{m}$ (for $H, K$ ).
} 
charge (see Bell, 1989) that could serve two additional functions. First, central attenuation at sites along the ascending central auditory pathway might function in "protection" against the loudness of self-generated vocalizations, as suggested for bats (Suga and Shimozawa, 1974). Second, as pointed out by Lin and Faber (1988), the activation of saccular efferents, which have inhibitory inputs to hair cells in goldfish, might participate in maintaining the sensitivity of hair cells to external sound sources since the hair cell-afferent nerve synapse habituates with repetitive stimulation (Furukawa and Matsura, 1978; Lin and Faber, 1988; also see Winslow and Sachs, 1987, for mammals). So far, the activation of saccular efferents has been described in the context of self-stimulatory, locomotor acts, that is, swimming. Saccular efferents may also be activated during sound production via vocal motor input to central efferent neurons. Given the long duration of midshipman mate calls (Bass, 1992), it would be advantageous to override the habituation likely induced by continuous self-generated sound to permit detection of conspecific signals. Finally, from an evolutionary perspective, the results presented here strongly imply that links between vocal and acoustic brain regions are traits common to endothermic vertebrates like mammals (Suga and Shimozawa, 1974; Metzner, 1993), and ectothermic vertebrates like teleost fishes, that vocalize.

\section{References}

Baker H, Spencer RF (1986) Transneuronal transport of peroxidaseconjugated wheat germ agglutinin (WGA-HRP) from the olfactory epithelium to the brain of the adult rat. Exp Brain Res 63:461-476.

Bass AH (1982) Evolution of the vestibulolateral lobe of the cerebellum in electroreceptive and nonelectroreceptive teleosts. J Morphol $174: 335-348$

Bass AII (1985) Sonic motor pathway in teleost fishes: a comparative HRP study. Brain Behav Evol 27:115-131.

Bass AH (1989) Evolution of vertebrate motor systems for acoustic and electric communication: peripheral and central elements. Brain Behav Evol 33:237-247.

Bass AH (1990) Sounds from the intertidal zone: vocalizing fish. Bioscience 40:249-258.

Bass AH (1992) Dimorphic male brains and alternative reproductive tactics in a vocalizing fish. Trends Neurosci 15:139-145.

Bass AH, Baker R (1990) Sexual dimorphisms in a vocal control system of a teleost fish: morphology of physiologically identified neurons. J Neurobiol 21:1155-1168.

Bass A, Baker R (1991) Evolution of homologous vocal control traits. Brain Behav Evol 38:240-254.

Bass AII, Marchaterre MA (1989) Sound-generating (sonic) motor system in a teleost fish (Porichthys notatus): sexual polymorphisms and general synaptology of sonic motor nucleus. J Comp Neurol 286: 154-169.

Bass AH, Marchaterre MA, Horvath BJ, Baker R (1992) Transneuronal biocytin outlines the vocal motor circuit in a teleost fish. Soc Neurosci Abstr 18:349.

Bell CC (1989) Sensory coding and corollary discharge effects in mormyrid electric fish. J Exp Biol 146:229-253.

Bennett N, Weiser M, Baker R, Bennett MVL (1985) Toadfish sonic motor system. I. Physiology. Biol Bull 169:546.

Cavanaugh GM (1956) Formulae and methods VI of the Marine Biological Laboratory. Woods Hole, MA: The Marine Biological Laboratory.

Collins WF III, Erichsen JT, Rose RD (1991) Pudendal motor and premotor neurons in the male rat: a WGA transneuronal study. J Comp Neurol 308:28-41.

Demski LS, Gerald JW (1974) Sound production and other behavioral effects of midbrain stimulation in free-swimming toadfish, Opsanus beta. Brain Behav Evol 9:41-59.
Echteler S (1984) Connections of the auditory midbrain in a teleost fish, Cyprinus carpio. J Comp Neurol 230:536-551.

Evinger C, Erichsen JT (1986) Transsynaptic retrograde transport of fragment $C$ of tetanus toxin demonstrated by immunohistochemical localization. Brain Res 380:383-388.

Fine ML (1979) Sounds evoked by brain stimulation in the oyster toadfish Opsanus tau. Exp Brain Res 35:197-212.

Fine ML, Winn H, Olla BL (1977) Communication in fishes. In: How animals communicate (Sebeok TA, ed), pp 472-518. Bloomington: Indiana UP.

Finger TE, Kalil K (1985) Organization of motoneuronal pools in the rostral spinal cord of the sea robin, Prionotus carolinus. J Comp Neurol 239:384-390.

Furukawa T, Matsura S (1978) Adaptive rundown of excitatory postsynaptic potentials at synapses between hair cells and eighth nerve fibers in the goldfish. J Physiol (Lond) 276:193-209.

Highstein SM, Baker R (1986) Organization of the efferent vestibular nuclei and nerves of the toadfish, Opsanus tau. J Comp Neurol 243: 309-325.

Highstein SM, Kitch R, Carey J, Baker R (1992) Anatomical organization of the brainstem octavolateralis area of the oyster toadfish, Opsanus tau. J Comp Neurol 319:501-518.

Hoover JE, Strick PL (1993) Multiple output channels in the basal ganglia. Science 259:819-821.

Horikawa K, Armstrong WE (1988) A versatile means of intracellular labeling: injection of biocytin and its detection with avidin conjugates. J Neurosci Methods 25:1-11.

Huang Q, Zhou D, DiFiglia M (1992) Neurobiotin, a useful neuroanatomical tracer for in vivo anterograde, retrograde and transneuronal tract-tracing and for in vitro labeling of ncurons. J Neurosci Methods $41: 31-43$

Izzo PN (1991) A note on the use of biocytin in anterograde tracing studies in the central nervous system: application at both light and electron microscopic level. J Neurosci Methods 36:155-166.

King MA, Louis PM, Hunter BE, Walker DW (1989) Biocytin: a versatile anterograde neuroanatomical tract-tracing alternative. Brain Res 497:361-367

Lapper SR, Bolam JP (1992) The anterograde and retrograde transport of neurobiotin in the central nervous system of the rat: comparison with biocytin. J Neurosci Methods 39:163-174.

Lin J-W, Faber DS (1988) An efferent inhibition of auditory afferents mediated by the goldfish Mauthner cell. Neuroscience 24:829-836.

Marchaterre M, Baker H, Baker R, Bass A (1989) Comparative neurochemical studies of the sonic motor system in teleost fishcs. Soc Neurosci Abstr 15:1137.

McCormick CA (1992) Evolution of central auditory pathways in anamniotes. In: The evolutionary biology' of hearing (Webster DB, Fay RR, Popper AN, eds), pp 323-350. New York: Springer.

McCormick CA, Braford MR Ir (1993) The primary octaval nuclei and inner ear afferent projections in the otophysan Ictalurus punctatus. Brain Behav Evol 42:48-68.

McCormick CA, Hernandcz, Braford MR Jr (1992) Acoustic areas in the hindbrain and midbrain of the goldfish. Soc Neurosci Abstr 18 : 327.

McDonald AJ (1992) Neuroanatomical labeling with biocytin: a review. Neuroreport 3:821-827.

Metzner W (1993) An audio-vocal interface in echolocating horseshoe bats. J Neurosci 13:1899-1915.

Pappas G, Bennett MVL (1966) Specialized junctions involved in electrical transmission between neurons. Ann NY Acad Sci 137:495508.

Popper AN, Fay RR (1993) Sound detection and processing by fish: critical review and major research questions. Brain Behav Evol 41: 14-38.

Roberts BL, Meredith GE (1992) The efferent innervation of the ear: variations on an enigma. In: The evolutionary biology of hearing (Webster DB, Fay RR, Popper AN, eds), pp 185-210. New York: Springer.

Suga N, Shimozawa T (1974) Site of neural attenuation of responses to self-vocalized sounds in echolocating bats. Science 183:1211-1213.

Vaney DI (1991) Many diverse types of retinal neurons show tracer coupling when injected with biocytin or Neurobiotin. Neurosci Lett 125:187-190. 
Weiser M, Bennett N, Bennett MVL, Baker R (1985) Toadfish sonic motor system. II. Morphology. Biol Bull 169:556-557.

Wiesel TN, Hubel DH, Lam DMK (1974) Autoradiographic demonstration of ocular-dominance columns in the monkey striate cortex by means of transneuronal transport. Brain Res 79:273-279.
Winslow RL, Sachs MB (1987) Effect of electrical stimulation of the crossed olivocochelar bundle on auditory nerve response to tones in noise. J Neurophysiol 57:1002-1021. 